\title{
Assessing the heavy metal contamination of soils in the water-level fluctuation zone upstream and downstream of the Manwan Dam, Lancang River
}

\author{
Shiliang Liu • Cong Wang • Juejie Yang • Qinghe Zhao
}

Received: 16 October 2013 / Accepted: 16 January 2014 / Published online: 4 February 2014

(C) Springer-Verlag Berlin Heidelberg 2014

\begin{abstract}
Purpose The intersections of the terrestrial and aquatic systems (water-level fluctuation zones, WLFZs) suffer from the increasing pressure of hydroelectric construction and operation. Taking WLFZs upstream and downstream of Manwan Dam (first dam completed in Lancang River) as an example, the dam operation impacts on the heavy metals in soils in WLFZs were assessed.

Materials and methods In December 2011, 117 soil samples were collected in the WLFZs and infralittoral reference zones (IRZs) with respect to heavy metal $(\mathrm{Cd}, \mathrm{Cr}, \mathrm{Cu}, \mathrm{Ni}, \mathrm{Pb}$ and $\mathrm{Zn}$ ) and metalloid (As) concentrations. Their concentrations were determined with the application of inductively coupled plasma atomic absorption spectrometry, ICP-AES. Enrichment factor (EF), ecological risk index (RI) and principal component analysis (PCA) were employed for element contamination and ecological risk assessment and source identification, respectively. The multivariable statistic approaches, an analysis of variance (ANOVA) and a paired-samples $T$ test were performed in the data analysis.
\end{abstract}

Responsible editor: Jean-Paul Schwitzguébel

S. Liu $(\bowtie) \cdot$ C. Wang $\cdot$ J. Yang $\cdot$ Q. Zhao

School of Environment, State Key Laboratory of Water Environment of Simulation, Beijing Normal University, Beijing 100875, China e-mail: shiliangliu@bnu.edu.cn

C. Wang

State Key Laboratory of Urban and Regional Ecology, Research Center for Eco-Environmental Sciences, Chinese Academy of

Sciences, Beijing 100085, China

J. Yang

School of Environment, Tsinghua University, Beijing 100084, China

Q. Zhao

College of Environment and Planning, Henan University,

Kaifeng 475004, China
Results and discussion Parts of element concentrations in the upstream were significantly higher than those in the downstream and significant differences existed between the WLFZs and IRZs. No significant difference was detected between the different water elevations in the WLFZs. Compared to the soil quality guidelines, As and Cd exceeded the standard in both the WLFZs and IRZs. In addition, the water-level fluctuation during the submergence increased the enrichment degree and risk level in the WLFZs. The sources of the studied elements could be divided into natural factors and anthropogenic inputs. In addition, the submergence changed the major contaminants in the upstream WLFZs.

Conclusions The results verified that dam operation had an effect on the heavy metals in the soils in WLFZs. In addition, this study proposed a useful tool (modified enrichment factor) to assess the enrichment degree caused by the water-level fluctuation. Assessing the heavy metal contamination of soils in WLFZs could be an important first step to the rational management of the dam operation.

Keywords Ecological risk · Enrichment factors · Heavy metal · Infralittoral reference zone · Manwan Dam •

Water-level fluctuation zone

\section{Introduction}

Hydroelectric dam construction has become a major driving force for social and environmental problems (Fearnside 2005). Terrestrial and aquatic systems suffer from the increasing pressure of hydroelectric construction (Bai et al. 2009). Heavy metals widely exist in the water, soil and plants in the riparian zone, which is the intersection of the terrestrial and aquatic ecosystems on earth's surface (Ye et al. 2013). In the non-flood season, the sources of heavy metals in the riparian zone are divided into two categories: natural weathering and 
anthropogenic activities, such as riverine discharge, domestic sewage and industrial wastewater (Feng et al. 2004; Zhang et al. 2007a). In the flood season, the inputs from human activities in the uplands and the aquatic environment heavy metals could be delivered to the riparian zone by flooding (Loska and Wiechula 2003) in addition to the natural origins. In different seasons, the load of these two sources might be different. Human activities have easily altered the heavy metal concentrations in the riparian environment (Mays and Edwards 2001; Zhang et al. 2009). Therefore, the heavy metal contamination in the riparian zone has attracted increasing concern in recent years.

Persistence, toxicity and non-degradability make the heavy metals serious pollutants in the environment (Tam and Wong 2000; Yuan et al. 2004). The toxicity and mobility of heavy metals in soils depend on the total concentration, their specific chemical form, their binding state, the metal properties, environmental factors and soil properties, redox conditions and root exudates acting as chelates (Nyamangara 1998; Rodríguez et al. 2009). Many research projects have been mainly focused on the spatial variation and assessing the heavy metals in the sediments and fresh water in the reservoir (Audry et al. 2004; Avila-Pérez et al. 1999; Karadede and Ünlü 2000; Loska and Wiechula 2003). In fact, the riparian zones have also been of great concern, as they can be an effective sink for heavy metals because of the integration and accumulation of pollutants from both the aquatic and terrestrial environments (Tam and Wong 2000). However, relatively few studies have centred on the riparian zones in river systems that were planned or constructed with cascade hydropower dams in which the riparian zones have been affected by regulating the reservoir water level and a prolonged water renewal time (Kummu and Varis 2007). In addition, some of the most widely used indicators for the estimation of anthropogenic inputs in the soils are enrichment factor (EF) and geoaccumulation index (Igeo) (Covelli and Fontolan 1997; Ghrefat and Yusuf 2006; Gonzáles-Macías et al. 2006). Based on this technique, metal concentrations were normalized to metal concentrations of average shale (Mwamburi 2003; Ghrefat and Yusuf 2006) or average crust (Gonzáles-Macías et al. 2006). However, the EF and Igeo method could only assess the difference between the concentration in the soils and background value, which could be considered as the overall impacts by the human activities. In other words, they could not specialize the heavy metal accumulation caused by water-level fluctuation.

The Lancang River is the largest international river in Asia. It originates from the eastern Tibetan Plateau in China and enters the South China Sea in the southern part of Vietnam (Zhang et al. 2007b). Cascade hydropower dams have been constructed on the mainstream of the Lancang River. The Manwan Dam was completed and began operation in 2000. The reservoir water level fluctuates from $982 \mathrm{~m}$ in summer
(June-September) to $984 \mathrm{~m}$ in winter (October-May), leading to the formation of the reservoir water-level fluctuation zones (WLFZs) (Gan et al. 2008; Zhao et al. 2011). WLFZs also exist downstream of the Manwan Dam, as the Dachaoshan Dam is located downstream of the Manwan Dam along the Lancang River. Previous studies have assessed the heavy metal contamination in riverine soils upstream and downstream of the Manwan Dam (Bai et al. 2009). Nevertheless, little information is available regarding the heavy metal contamination in the WLFZs and their variations between different elevations upstream and downstream. In this study, the adjacent zones above the WLFZs that were not subjected to submergence were considered as were the infralittoral reference zones (IRZs); thus, we could examine the impact of the water-level fluctuation on the WLFZs heavy metals by comparing the heavy metal conditions in the WLFZs and in the IRZs.

The goals of this study are as follows: (1) to explore the spatial variation of heavy metals in WLFZs upstream and downstream and at different water elevations; (2) to assess the extent of contamination of the heavy metals using soil quality guidelines, enrichment factors and the ecological risk index; (3) to identify sources of contamination; and (4) to propose a convenient method to assess the water-level fluctuation impact on heavy metal accumulation.

\section{Materials and methods}

\subsection{Study area}

In the upper Lancang River Basin, the river elevation drops dramatically with an average gradient of $0.15 \%$. The study area is subject to a monsoon climate and periodic rainstorms in which the overall rainfall is plentiful, and approximately $70 \%$ of precipitation occurs in the summer (He et al. 2006). The Manwan Dam was the first dam of the Lancang mainstream cascade development project, as well as the first multimillion kilowatt hydropower station in the Yunnan Province; the station is located in the middle reaches of the Lancang River (Fig. 1). Recently, some negative effects have been detected in both upstream and downstream areas of the Manwan Dam, such as landscape devastation and potential geological hazards (He et al. 2006; Xu and Chen 2005).

\subsection{Sampling and analytical methods}

To investigate the heavy metals in the WLFZs upstream and downstream of the Manwan Dam, soil samples were collected in December 2011, when the WLFZs were exposed to the air after submergence. A total of 39 sampling sites (pairwise in the WLFZs and corresponding IRZs) were selected upstream (S1-S21) and downstream (X1-X18) of the Manwan Dam 


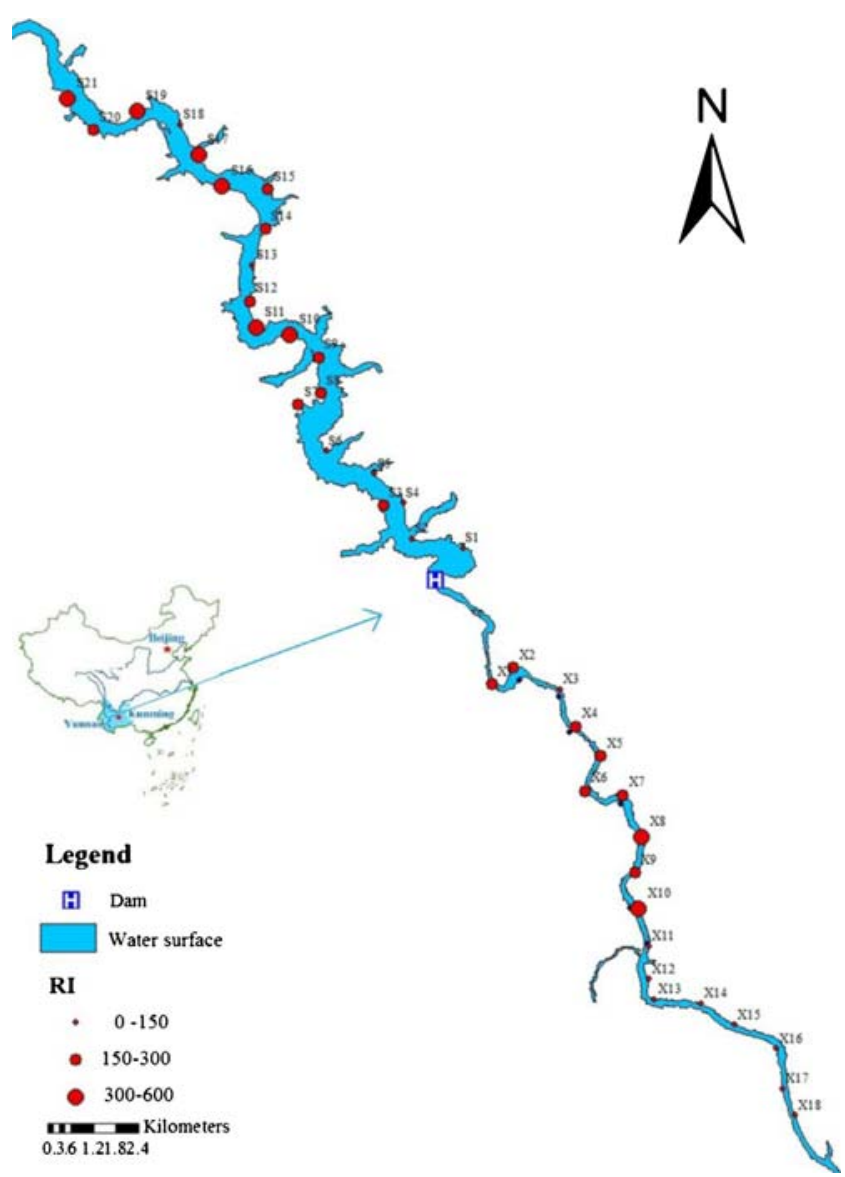

Fig. 1 Location of the Manwan Dam and the sample sites, Yunnan Province, China. The red solid circles describe the sampling sites, and the size indicates the potential ecological risk

(Fig. 1). At each site, three sampling plots $(1 \mathrm{~m} \times 1 \mathrm{~m})$ were selected with an interval of $1 \mathrm{~m}$ in elevation. At each plot, we collected five top soil samples (i.e. 0-20 cm), and the samples were well mixed to form a composite sample. All samples were sealed in plastic bags and stored at $4{ }^{\circ} \mathrm{C}$ for analysis. Before determining the soil heavy metals, all samples were air dried at room temperature, and the air-dried samples were ground until all particles passed a 100-mesh nylon sieve after the coarse debris was removed. The dried sediment sample was placed into a closed Teflon vessel with $3-\mathrm{mL} \mathrm{HNO}_{3}$ (1.42 g/mL), 2-mL $\mathrm{HClO}_{4}(1.49 \mathrm{~g} / \mathrm{mL})$, and $1-\mathrm{mL} \mathrm{HF}$ $(1.68 \mathrm{~g} / \mathrm{mL})$ acids. Then, the vessels were placed inside a well-closed stainless steel block and heated on a thermostatically controlled hot plate at $70{ }^{\circ} \mathrm{C}$ for approximately $12 \mathrm{~h}$ (Oregioni and Aston 1984). After the HF was eliminated with $2-\mathrm{mL} \mathrm{H}_{2} \mathrm{SO}_{4}(1.07 \mathrm{~g} / \mathrm{mL})$, the residue was redissolved to a specific volume with diluted $\mathrm{HNO}_{3}$ in vinyl-chloride bottles and filtered. For each digestion programme, a blank was prepared using the same procedure. The heavy metal concentrations (i.e. As, $\mathrm{Cd}, \mathrm{Cr}, \mathrm{Cu}, \mathrm{Fe}, \mathrm{Ni}, \mathrm{Pb}$ and $\mathrm{Zn}$ ) in the solutions were determined using the SEPAC method HJ/T 166-2004 (inductively coupled plasma atomic absorption spectrometry,
ICP-AES) (SEPAC 2004). Quality control was performed by a parallel analysis of the standard reference material (GBW07401) obtained from the Chinese Academy of Measurement Sciences, and a good agreement was observed (the analytical precision was within $\pm 5 \%$ ).

\subsection{Data analysis}

To assess the level of contamination within the WLFZs and IRZs, an enrichment factor (EF) was used. The EF concept was developed to evaluate the degree of anthropogenic contribution to heavy metal contamination (Zoller et al. 1974). The formula is

$\mathrm{EF}=\frac{E \mathrm{~s} / \mathrm{Fes}}{E \mathrm{a} / \mathrm{Fea}}$

where $E_{\mathrm{s}} / \mathrm{Fe}_{\mathrm{s}}$ is the examined element to $\mathrm{Fe}$ ratio in the WLFZs sample and $E_{\mathrm{a}} / \mathrm{Fe}_{\mathrm{a}}$ is the examined element to $\mathrm{Fe}$ ratio in the reference environment. Because $\mathrm{Fe}$ is inert in the migration process and originates mainly from natural lithogenic sources, Fe was selected as the reference element. In the present study, the background concentrations in the Yunnan Province were used as the reference (Table 1). The Fe background concentration was $52,200 \mathrm{mg} / \mathrm{kg}$. According to Birch's suggested criteria (Birch 2003), EF $<1$ was considered as no enrichment; $1 \leq \mathrm{EF}<3$, as minor enrichment; $3 \leq \mathrm{EF}$ $<5$, as moderate enrichment; $5 \leq \mathrm{EF}<10$, as moderately severe enrichment; and $10 \leq \mathrm{EF}<25$, as severe enrichment.

To assess the ecological risks caused by heavy metals in the WLFZs, the ecological risk index (RI) suggested by Hakanson (1980) was applied in the present study. This index considers the toxicity of the heavy metals and the response of the environment by using a toxic response factor for a given substance (Hakanson 1980). The RI is defined as follows:

$\mathrm{RI}=\sum_{i=1}^{n}(T i \times \mathrm{Cf} i)=\sum_{i=1}^{n}\left(T i \times \frac{C s^{i}}{C n^{i}}\right)$

where $T_{i}$ is the toxic response factor for a given substance, and $\mathrm{Cf}_{i}$ is the contamination factor (a ratio between preindustrial soil records $\left(C_{n}{ }^{i}\right)$ and present concentration values $\left.\left(C_{s}{ }^{i}\right)\right)$. The toxic response factor $\left(T_{i}\right)$ for $\mathrm{Cr}, \mathrm{Cu}, \mathrm{Ni}, \mathrm{Zn}, \mathrm{Pb}, \mathrm{As}$ and $\mathrm{Cd}$ is 2, 5, 5, 1, 5, 10 and 30, respectively (Qiao et al. 2005). The reference values for the background records were obtained from the background values of soils in the Yunnan Province (Table 1). According to Hakanson (1980), the following definitions are suggested for the RI value: $\mathrm{RI} \leq 150$, low ecological risk; $150<\mathrm{RI} \leq 300$, moderate ecological risk; $300<\mathrm{RI} \leq$ 600, high ecological risk; and RI $>600$, significantly high ecological risk.

In addition, multivariable statistic approaches were performed for further analysis. The paired-samples $T$ test was 


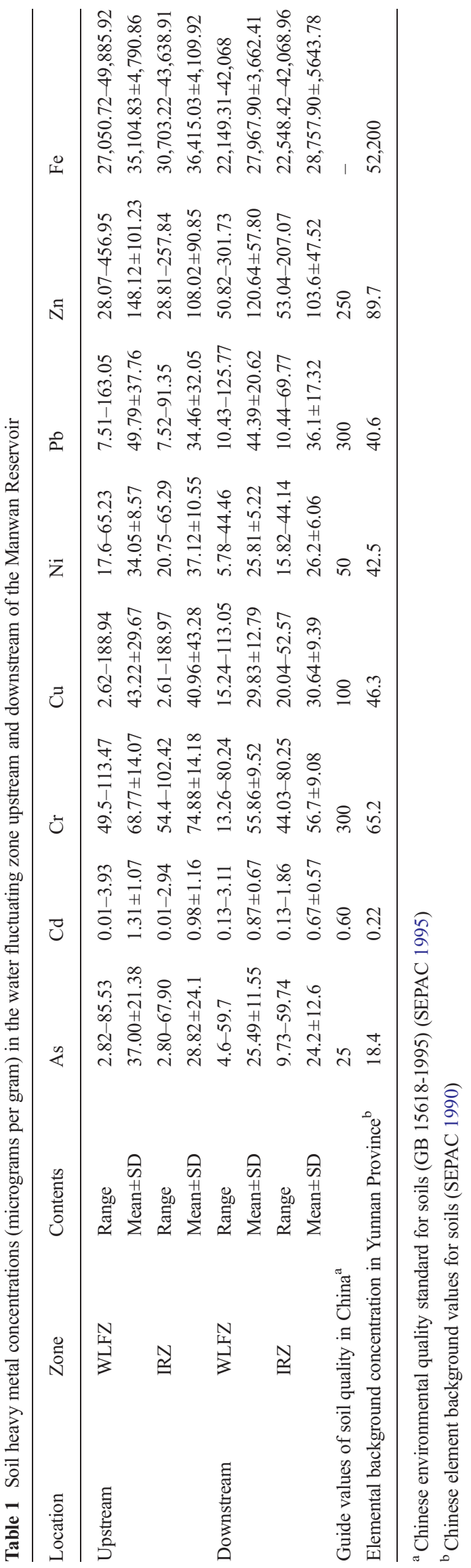

performed to compare the metal concentrations in the WLFZs and IRZs. A one-way ANOVA was used to examine the spatial variation of the metals. Principal component analysis (PCA) was used to identify their sources. The Kaiser-MeyerOlkin (KMO) and Bartlett's sphericity tests were performed to examine the suitability of the data. All data analyses were conducted using SPSS 15.0.

\section{Results and discussion}

3.1 Heavy metal concentrations in WLFZs and IRZs upstream and downstream of the Manwan Dam

The statistical characteristics of the average $\mathrm{As}, \mathrm{Cd}, \mathrm{Cr}, \mathrm{Cu}$, $\mathrm{Ni}, \mathrm{Pb}, \mathrm{Zn}$ and $\mathrm{Fe}$ concentrations in the upstream and downstream WLFZs and IRZs of the Manwan Dam are shown in Table 1. As shown in Table 1, there was a distinct change in the contents of heavy metals among the sampling soils, $\mathrm{Cd}$ and $\mathrm{Zn}$ had relatively higher coefficients of variation, and $\mathrm{Cr}$ and Ni had relatively lower coefficients of variation, both in the WLFZs and IRZs. As the soil quality guidelines reflect the importance of contaminated soils as a possible cause for adverse environmental effects (Youssef and El-Said 2011), we compared the observed heavy metal concentrations in the samples with the second grade of Chinese soil quality standards (GB15618-1995) (SEPAC 1995), as class II was for safeguarding human health. The results showed that the As and Cd sampled in both the IRZs and WLFZs in the study area exceeded the second grade and could be related to the high emission from anthropogenic activities. Moreover, the average $\mathrm{Cu}$ and $\mathrm{Ni}$ concentrations in the downstream WLFZs and IRZs were relatively lower than the Yunnan Province background concentrations, while Cd concentrations in the WLFZ and IRZ and the Zn concentration in the WLFZ were obviously higher upstream (SPEAC 1990).

The spatial variation of heavy metals in the upstream and downstream WLFZs and IRZs is shown in Fig. 2. The average concentrations of $\mathrm{As}, \mathrm{Cd}, \mathrm{Cr}, \mathrm{Cu}, \mathrm{Ni}, \mathrm{Pb}, \mathrm{Zn}$ and $\mathrm{Fe}$ were higher in the upstream WLFZ than those in the downstream WLFZ. In addition, the ANOVA results showed that As, Cr, $\mathrm{Cu}, \mathrm{Ni}$ and $\mathrm{Fe}$ levels in the upstream WLFZ were significantly different $(P<0.05, P<0.01)$ from those in the downstream WLFZ (Fig. 2a), which means that these heavy metals revealed spatial variation, as the lithology type was the same and classified as rhyolite (Fang 1998) and the soil type was latosolic red soil (NSSO 1995) in the study area. In addition, no evidence revealed that heterogeneous parent materials existed there, and it might be concluded that spatial variation did not relate with the local geochemical background of heavy metal. Thus, the spatial variation could be attributed to the Manwan Dam trapping the heavy metals and the fast flow velocity in the adjacent downstream waters (Bai et al. 2009; Zhang et al. 


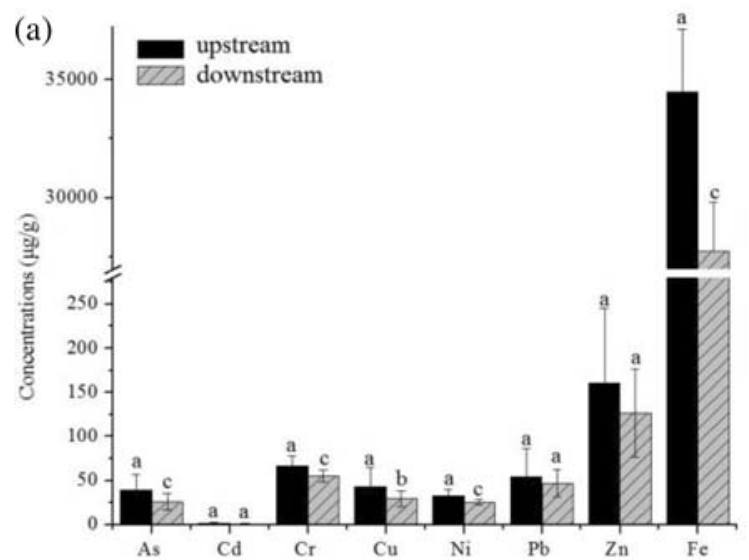

Fig. 2 a Average concentrations of heavy metals in WLFZs upstream and downstream of the Manwan Dam (micrograms per gram). b Average concentrations of the heavy metals in IRZs upstream and downstream of the Manwan Dam (micrograms per gram). $a$ indicates that there is no

2005). The concentrations of the studied heavy metals (except $\mathrm{Pb}$ ) were higher in the upstream IRZ than those in the downstream IRZ. The ANOVA results revealed that the $\mathrm{Cr}, \mathrm{Ni}$ and Fe concentrations showed significant variations between the upstream and downstream IRZs; such variations might be related to different sources and land use changes, as more crop lands existed in the upstream compared with those in the downstream, resulting in more use of fertilizer containing $\mathrm{Fe}$ in the upstream, relatively.

\subsection{Variation between the WLFZs and IRZs}

A paired-samples $T$ test was applied to compare the heavy metals in the WLFZs and IRZs in the upstream and downstream regions of the Manwan Dam. The results indicated that the $\mathrm{As}, \mathrm{Cd}, \mathrm{Cu}, \mathrm{Pb}$ and $\mathrm{Zn}$ concentrations increased, while the $\mathrm{Cr}$ and Ni decreased in the upstream WLFZ compared with those in the IRZ. Furthermore, Cr showed a significant variation $(P<0.01)$ between the WLFZ and IRZ upstream of the Manwan Dam (Fig. 3a). Additionally, heavy metals in the downstream region showed similar patterns to those in the upstream. Chromium, $\mathrm{Pb}$ and $\mathrm{Zn}(P<0.01, P<0.05)$ concentrations in the WLFZ were significantly different from those in the IRZ downstream of the Manwan Dam (Fig. 3b). These results partly demonstrated the impacts of water-level fluctuations during the submergence period on the heavy metal concentrations in the WLFZs, which could be further explained as the heavy metal deposition from the water in the reservoir (Ye et al. 2011).

Heavy metal variations between different water elevations in the upstream and downstream WLFZs were also evaluated by the paired-samples $T$ test. The results showed that there were no significant differences between different water elevations in both the upstream and downstream WLFZs (Fig. 4). These results are in accordance with the study in the Three

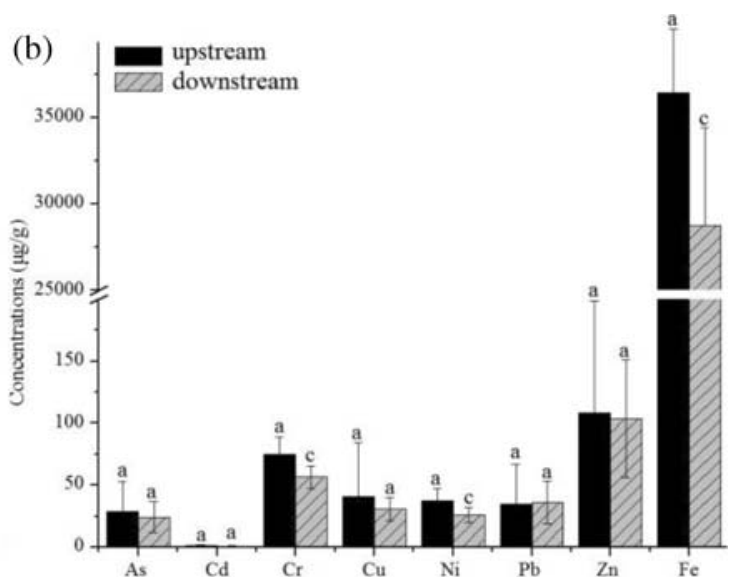

significant difference between upstream and downstream; $b$ indicates a significant difference at the 0.05 level; $c$ indicates a significant difference at the 0.01 level

Gorges Reservoir by Wang (2012b); this result could be due to the insufficient flooding time to impact the heavy metal variations in different water levels (Wang et al. 2010, 2012b), or because the water elevation interval in this study area was too small to reveal significant variations.

\subsection{Enrichment degree assessment}

The enrichment factors for this study were calculated for the upstream and downstream WLFZs and IRZs. The EF values are shown in Table 2. The order of the average enrichment degree for different metals in the upstream WLFZ was $\mathrm{Cd}>$ $\mathrm{As}>\mathrm{Zn}>\mathrm{Pb}>\mathrm{Cr}>\mathrm{Cu}>\mathrm{Ni}$, and the order was $\mathrm{Cd}>\mathrm{As}=\mathrm{Zn}$ $>\mathrm{Pb}>\mathrm{Cr}>\mathrm{Cu}>\mathrm{Ni}$ downstream. In the upstream WLFZ, $\mathrm{Cd}$ fell into the moderately severe enrichment group; As fell into the moderate enrichment group; and $\mathrm{Cr}, \mathrm{Cu}, \mathrm{Ni}, \mathrm{Pb}$ and $\mathrm{Zn}$ fell into the minor enrichment group. In the downstream WLFZ, $\mathrm{Cd}$ belonged to the moderately severe enrichment group; and $\mathrm{As}, \mathrm{Cr}, \mathrm{Cu}, \mathrm{Ni}, \mathrm{Pb}$ and $\mathrm{Zn}$ belonged to the minor enrichment group. Overall, the enrichment level in the upstream WLFZ was higher than that in the downstream WLFZ. Comparing the EF values in the WLFZ and those in IRZ (Table 2), results showed that the enrichment level in the WLFZs was relatively higher than that in the IRZs for almost all of the studied elements both upstream and downstream, suggesting that the water-level alteration caused by the dam operation brought additional sources of heavy metals into the WLFZs soils (Ye et al. 2011).

The distributions of the heavy metal enrichment factors in the upstream and downstream WLFZs of the Manwan Dam are presented in Fig. 5. As shown in Fig. 5, the enrichment factors of elements $\mathrm{As}, \mathrm{Cd}, \mathrm{Pb}$ and $\mathrm{Zn}$ revealed quite similar trends in both the upstream and downstream WLFZs; this similarity could be related to their similar anthropogenic sources and the similar properties of some metals (Wang 
Fig. 3 a Average heavy metal concentrations in the WLFZ and IRZ upstream of the Manwan Dam (micrograms per gram). b Average heavy metal concentrations in the WLFZ and IRZ downstream of the Manwan Dam (micrograms per gram). $a$ indicates that there is no significant difference between the WLFZs and IRZs; $b$ indicates a significant difference at the 0.05 level; $c$ indicates a significant difference at the 0.01 level
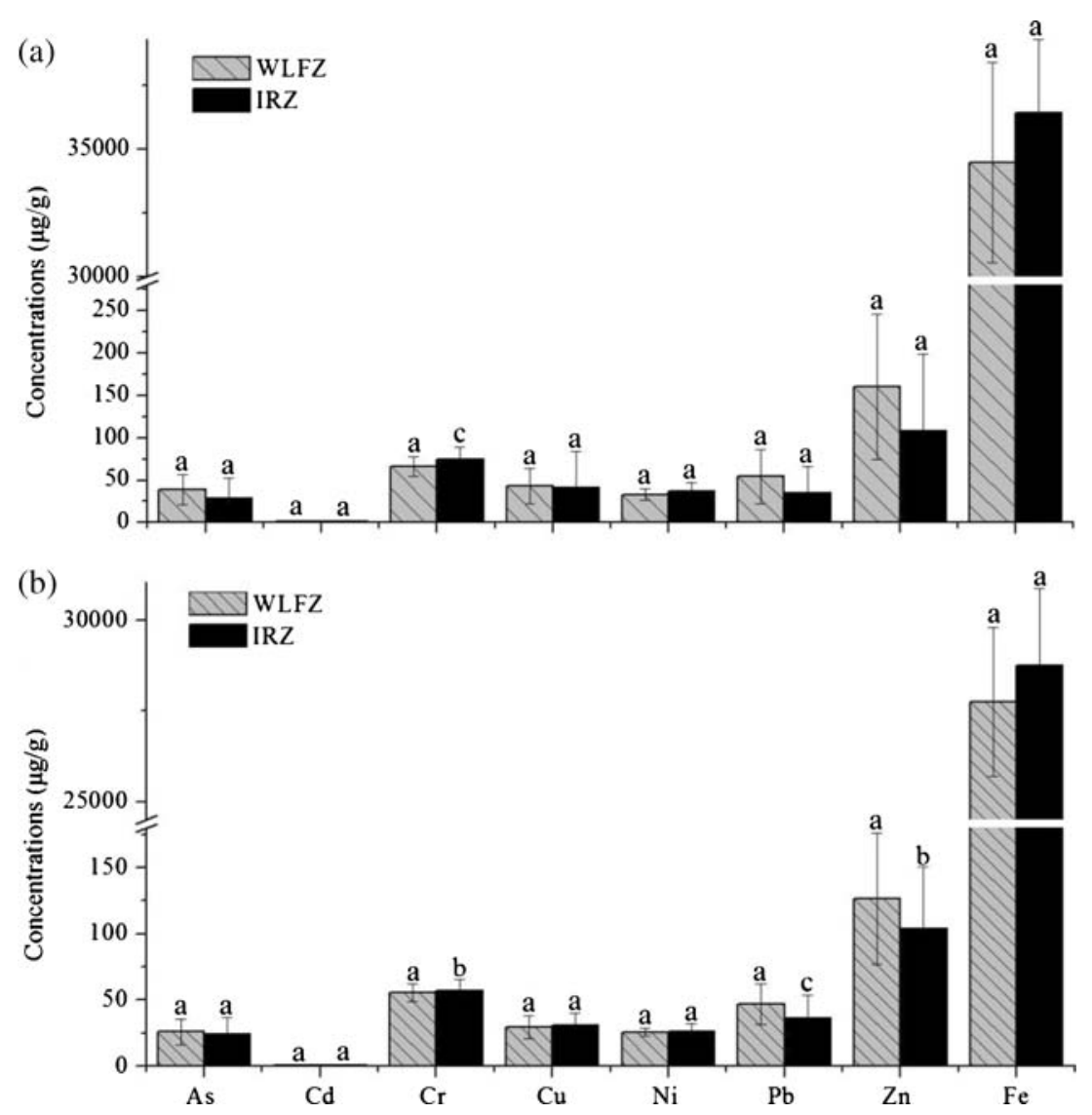

et al. 2012a). In addition, the above elements in the upstream WLFZ had relatively higher EF values at S9 and S21, as the residential area located at $\mathrm{S} 21$ led to more untreated sewage discharge and the tributaries adjacent to S9 contributed heavy metals to the mainstream. In the downstream WLFZ, higher $\mathrm{EF}$ values for $\mathrm{As}, \mathrm{Cd}, \mathrm{Pb}$ and $\mathrm{Zn}$ were found at $\mathrm{X} 8$ and $\mathrm{X} 10$; these higher values could be attributed to the chemical fertilizer application in the adjacent farmlands (Srinivasa Gowd et al. 2010, Zhao 1996). As for $\mathrm{Cr}, \mathrm{Cu}$ and $\mathrm{Ni}$, the $\mathrm{EF}$ values were relatively lower, ranging from 1.1 to 1.6 , both in the upstream and downstream WLFZs; therefore, these metals might come from crustal materials or natural weathering (Acevedo-Figueroa et al. 2006).

\subsection{Source identification}

PCA identifies the correlations among the original variables in a data set and leads to an easier interpretation. PCA was performed for the heavy metals in the WLFZs upstream and downstream of the Manwan Dam. The results showed that heavy metal concentrations in the upstream WLFZs could be represented with two main components, which accounted for $76.92 \%$ of the total variance (Table 3 ). The first component, with a variance of $46.48 \%$, was highly correlated with As, Cd, $\mathrm{Pb}$ and $\mathrm{Zn}$. This component could be identified as an "anthropogenic factor" and might originate from a common source due to hydroelectric development (Bai et al. 2009). The second component accounted for $30.44 \%$ of the total variance with high loadings on $\mathrm{Cr}, \mathrm{Ni}$ and $\mathrm{Fe}$. We can label this component the "natural factor", as Fe belongs to the lithogenous components; therefore, their metal concentrations might be controlled by the parent rock composition (Rubio et al. 2000; Wang et al. 2012a). Copper was divided between the two components, suggesting that $\mathrm{Cu}$ was contributed by both natural and anthropogenic sources. On the other hand, in the downstream WLFZs (Table 3), $73.98 \%$ of the cumulative variance was explained by the first two principal components. PC1 accounted for $47.86 \%$ of the total variance; had the highest loadings of $\mathrm{As}, \mathrm{Cd}, \mathrm{Pb}$ and $\mathrm{Zn}$; and could also be identified as an "anthropogenic factor". PC2 accounted for approximately $26.12 \%$ of the total variance with the highest loadings of $\mathrm{Cr}$ and $\mathrm{Ni}$ and could be considered as a "natural factor", as the background concentrations in this study area were relatively higher (Table 1) (SEPAC 1990). Cu and Fe revealed intermediate loadings of $\mathrm{PC} 1$ and were also represented in PC2, indicating that their sources could be both natural and anthropogenic.

Comparing the heavy metal source identification results of the upstream and downstream WLFZs, results showed that the heavy metal sources in the upstream and downstream WLFZs 

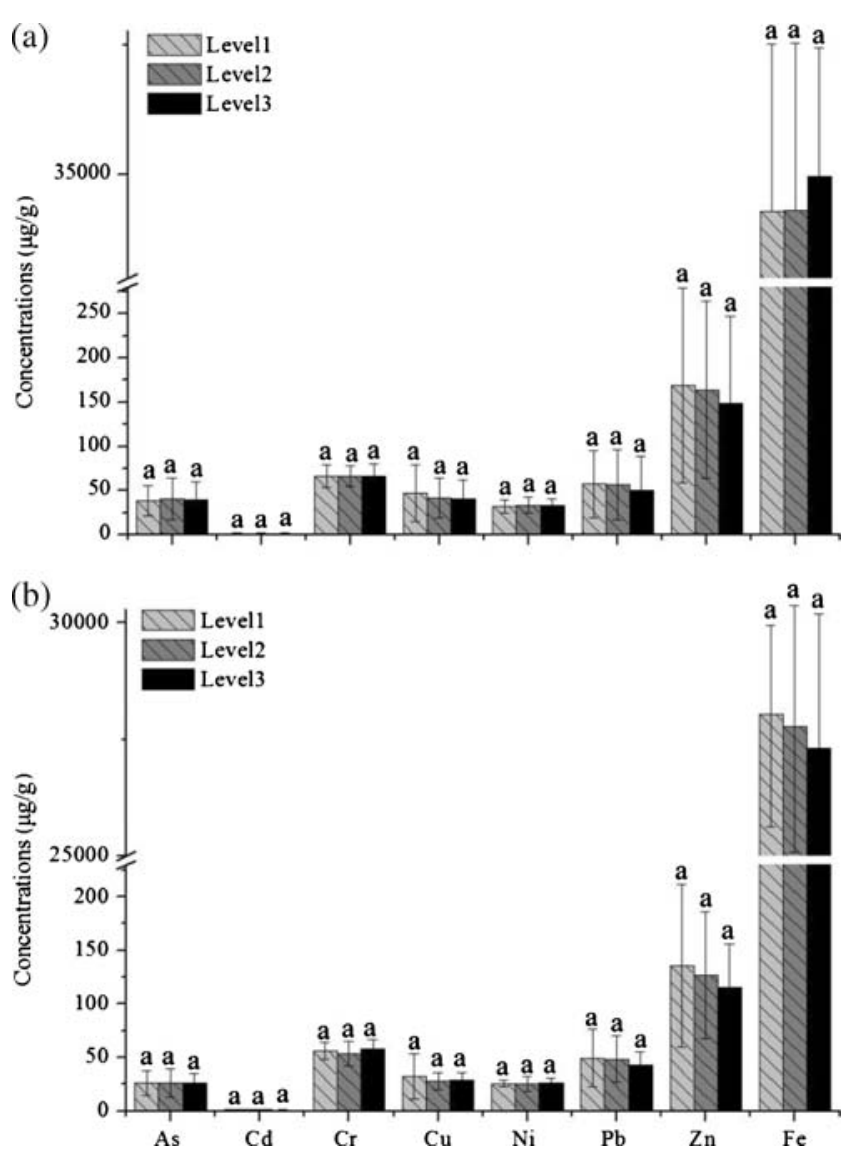

Fig. 4 a Average heavy metal concentrations at different elevations in the WLFZ upstream of the Manwan Dam (micrograms per gram). b Average heavy metal concentrations at different elevations in the WLFZ downstream of the Manwan Dam (micrograms per gram); $a$ indicates that there is no significant difference among the three elevation levels

were basically consistent, indicating that the Manwan Dam did not impose significant impacts. In addition, the anthropogenic sources could be further specified. The application of fertilizers or pesticides in agricultural activities (Tongke 1996), the metal mining and smelting industries ( $\mathrm{Li} \mathrm{1999;}$ Yanqun et al. 2005), the pigment and electroplating industries (Lin et al. 2002) and the exploitation of the Heihui River (located upstream of the Manwan Reservoir) (Zhao et al. 2012) mainly contributed to the relatively higher concentrations of $\mathrm{As}, \mathrm{Cd}, \mathrm{Pb}$ and $\mathrm{Zn}$.

The IRZs represented the conditions that were not subject to submergence. The possible sources of heavy metals in IRZs were

Table 2 Mean values of each element EF at upstream and downstream WLFZs and IRZs of Manwan Dam

\begin{tabular}{lllllllll}
\hline & EF & As & $\mathrm{Cd}$ & $\mathrm{Cr}$ & $\mathrm{Cu}$ & $\mathrm{Ni}$ & $\mathrm{Pb}$ & $\mathrm{Zn}$ \\
\hline Upstream & WLFZ & 3.23 & 9.76 & 1.54 & 1.41 & 1.18 & 2.03 & 2.70 \\
& IRZ & 2.25 & 6.39 & 1.65 & 1.27 & 1.25 & 1.22 & 1.73 \\
Downstream & WLFZ & 2.66 & 8.13 & 1.60 & 1.20 & 1.13 & 2.18 & 2.66 \\
& IRZ & 2.39 & 5.51 & 1.58 & 1.20 & 1.12 & 1.62 & 2.10
\end{tabular}

also identified through PCA (Table 4), and the results were compared with those of the WLFZs. In the IRZs, two factors were obtained, accounting for $80.59 \%$ of the total variance in the upstream region and $80.96 \%$ in the downstream region. In the upstream IRZ, factor 1, accounting for $62.25 \%$ of the total variance, has the highest loadings of $\mathrm{As}, \mathrm{Cd}, \mathrm{Cr}, \mathrm{Pb}$ and $\mathrm{Zn}$, medium loadings of $\mathrm{Ni}$ and $\mathrm{Fe}$ and can be considered as an anthropogenic factor. Factor 2, accounting for $18.34 \%$ of total variance with the highest loadings of $\mathrm{Cu}$ and intermediate loadings of $\mathrm{Fe}$ and As, could be identified as a natural factor. In the downstream IRZ, factor 1, accounting for $40.92 \%$ of the total variance, has the highest loadings of $\mathrm{Cr}, \mathrm{Cu}$ and $\mathrm{Ni}$ and medium loadings of As, and $\mathrm{Fe}$ and can be considered as a natural factor. Factor 2, which accounts for $40.04 \%$ of the total variance with the highest loadings of $\mathrm{Cd}, \mathrm{Pb}$ and $\mathrm{Zn}$ and intermediate loadings of As, could be considered a anthropogenic factor.

Comparing the heavy metal source identification results in the IRZs with those in the WLFZs, results showed that the primary pollutants changed from $\mathrm{As}, \mathrm{Cd}, \mathrm{Cr}, \mathrm{Pb}$ and $\mathrm{Zn}$ to $\mathrm{As}$, $\mathrm{Cd}, \mathrm{Pb}$ and $\mathrm{Zn}$ after submergence upstream, while the primary pollutants were basically consistent after submergence downstream. The transformation could be partly attributed to material exchange due to the submergence in the WLFZ (Censi et al. 2006; Qiao et al. 2007; Ye et al. 2011).

\subsection{Potential ecological risk assessment}

The RI values for all sample sites in the upstream and downstream WLFZs of the Manwan Dam were calculated and plotted in Fig. 1 using the geographic information system software. The results showed that six sites revealed high ecological risk (S10, S11, S16, S17, S19 and S21), eight sites revealed moderate ecological risk (S3, S7, S8, S9, S12, S14 and $\mathrm{S} 15$ ), and the remaining revealed a low ecological risk in the upstream WLFZ. In addition, two sites revealed a high ecological risk (X8 and X10), seven sites revealed moderate ecological risk (X1, X2, X4, X5, X6, X7 and X9) and the rest revealed a low ecological risk in the downstream WLFZ. The distribution plot was quite conducive for identifying the sites that need more attention and monitoring in our study area.

Comparing the RI values in upstream and downstream WLFZs (Fig. 1), results showed that the upstream WLFZ revealed a higher ecological risk, which could be partly related to the dam trap of the heavy metals in the river. In addition, the average RI values in the WLFZs and IRZs upstream and downstream were also calculated. The average RI values in upstream and downstream WLFZs were 234 and 166, respectively. The average RI values in upstream and downstream IRZs were 159 and 118, respectively. The results showed that the WLFZs had relatively higher ecological risks than the IRZs, which indicated that the water-level fluctuation increased the risk level in the WLFZs during the submergence period. 

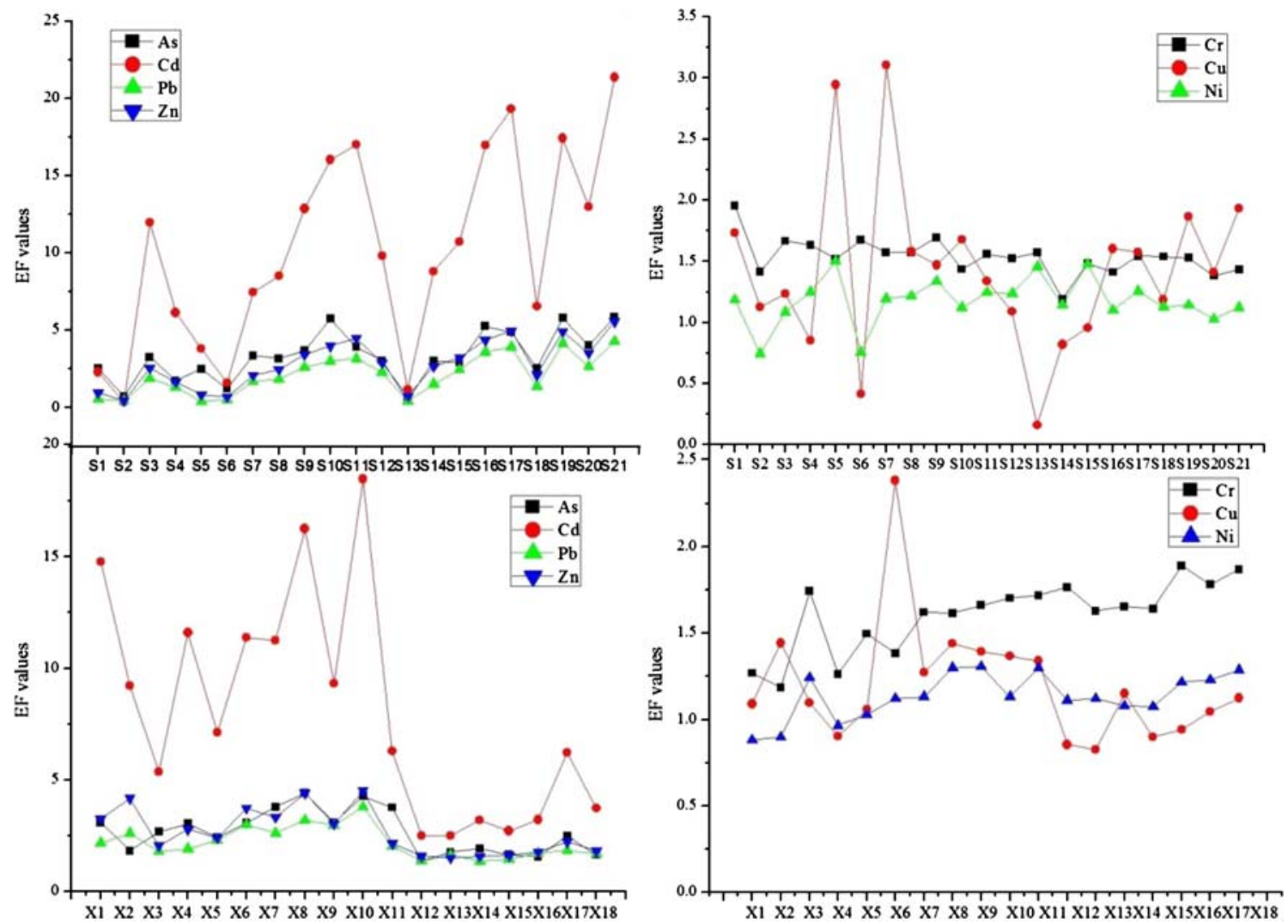

Fig. $5 \mathrm{EF}$ values of the elements in the sample sites in the upstream and downstream WLFZs of the Manwan Dam. The upstream sites are represented above, and the downstream sites are represented below

\subsection{A modified enrichment factor equation}

Calculating the EF for heavy metals above uncontaminated background levels is a common approach for estimating the anthropogenic impact on soils (Dickinson et al. 1996). This research attempted to plot geochemical trends in the WLFZs induced by the water-level fluctuation. A modified form of the enrichment factor equation was presented to calculate the

Table 3 Varimax-rotated factor loading (PCA) and identified sources of heavy metals in soils of the upstream and downstream WLFZs of the Manwan Reservoir, China

\begin{tabular}{|c|c|c|c|c|c|}
\hline \multicolumn{3}{|l|}{ Upstream } & \multicolumn{3}{|l|}{ Downstream } \\
\hline Variable & Factor 1 & Factor 2 & Variable & Factor 1 & Factor 2 \\
\hline As & 0.93 & -0.15 & As & 0.79 & 0.26 \\
\hline $\mathrm{Cd}$ & 0.92 & -0.29 & $\mathrm{Cd}$ & 0.96 & -0.01 \\
\hline $\mathrm{Cr}$ & -0.20 & 0.87 & $\mathrm{Cr}$ & -0.14 & 0.92 \\
\hline $\mathrm{Cu}$ & 0.43 & 0.24 & $\mathrm{Cu}$ & 0.59 & 0.15 \\
\hline $\mathrm{Ni}$ & -0.05 & 0.78 & $\mathrm{Ni}$ & 0.18 & 0.91 \\
\hline $\mathrm{Pb}$ & 0.92 & -0.29 & $\mathrm{~Pb}$ & 0.92 & 0.17 \\
\hline $\mathrm{Zn}$ & 0.93 & -0.26 & $\mathrm{Zn}$ & 0.97 & -0.04 \\
\hline $\mathrm{Fe}$ & -0.20 & 0.87 & $\mathrm{Fe}$ & 0.32 & 0.55 \\
\hline Eigenvalue & 4.45 & 1.71 & Eigenvalue & 4.03 & 1.89 \\
\hline Percent of variance & 46.48 & 30.44 & Percent of variance & 47.86 & 26.12 \\
\hline Cumulative percentage & 46.48 & 76.92 & Cumulative percentage & 47.86 & 73.98 \\
\hline Possible source & Anthropogenic factor & Natural factor & Possible source & Anthropogenic factor & Natural factor \\
\hline
\end{tabular}


Table 4 Varimax-rotated factor loading (PCA) and identified sources of heavy metals in soils of the upstream and downstream IRZs of the Manwan Dam, China

\begin{tabular}{|c|c|c|c|c|c|}
\hline \multicolumn{3}{|l|}{ Upstream } & \multicolumn{3}{|l|}{ Downstream } \\
\hline Variable & Factor 1 & Factor 2 & Variable & Factor 1 & Factor 2 \\
\hline As & 0.84 & 0.48 & As & 0.72 & 0.54 \\
\hline $\mathrm{Cd}$ & 0.96 & -0.03 & $\mathrm{Cd}$ & -0.03 & 0.98 \\
\hline $\mathrm{Cr}$ & -0.85 & -0.21 & $\mathrm{Cr}$ & 0.88 & -0.12 \\
\hline $\mathrm{Cu}$ & 0.22 & 0.93 & $\mathrm{Cu}$ & 0.84 & 0.26 \\
\hline $\mathrm{Ni}$ & -0.56 & -0.09 & $\mathrm{Ni}$ & 0.92 & 0.01 \\
\hline $\mathrm{Pb}$ & 0.96 & 0.10 & $\mathrm{~Pb}$ & 0.06 & 0.98 \\
\hline $\mathrm{Zn}$ & 0.94 & 0.02 & $\mathrm{Zn}$ & 0.07 & 0.97 \\
\hline $\mathrm{Fe}$ & -0.66 & 0.55 & $\mathrm{Fe}$ & 0.64 & -0.03 \\
\hline Eigenvalue & 5.07 & 1.37 & Eigenvalue & 3.82 & 2.66 \\
\hline Percent of variance & 62.25 & 18.34 & Percent of variance & 40.92 & 40.04 \\
\hline Cumulative percentage & 62.25 & 80.60 & Cumulative percentage & 40.92 & 80.96 \\
\hline Possible source & Anthropogenic factor & Natural factor & Possible source & Anthropogenic factor & Natural factor \\
\hline
\end{tabular}

contamination level in the WLFZs caused by the water-level fluctuation as follows:

$\mathrm{mEF}=\frac{E \mathrm{WLFZ} / \mathrm{FeWLFZ}}{E \mathrm{IRZ} / \mathrm{FeIRZ}}$

where $E_{\mathrm{WLFZ}}$ and $\mathrm{Fe}_{\mathrm{WLFZ}}$ are the soil sample concentrations of the heavy metals and $\mathrm{Fe}$ (or other normalizing element) in the WLFZs, respectively, and $E_{\text {IRZ }}$ and $\mathrm{Fe}_{\mathrm{IRZ}}$ are their concentrations in the corresponding IRZs. For the classification and description of the modified degree of contamination $(\mathrm{mEF})$ in the WLFZ soils, the following gradations are proposed: $\mathrm{mEF} \leq 1$, nil to a very low degree of enrichment; $1<$ $\mathrm{mEF} \leq 3$, minor enrichment; and $3<\mathrm{mEF} \leq 5$, moderate enrichment.
The mEFs for the heavy metals in the WLFZs were calculated according to Eq. 3 and are shown in Fig. 6. The results showed that most heavy metals in the upstream WLFZ revealed similar patterns (except Ni in the upstream) in most sample sites and that they are more conspicuous in the downstream WLFZ, indicating that their distribution patterns were mainly affected by one major factor: the water-level fluctuation. The above results validated the proposed modified equation. However, some different trends at some of the sites are detected in Fig. 6. These different trends might be attributed to the differences in the topography and management practices at these sites.

Overall, this study proposed a convenient tool to assess the heavy metal accumulation caused by the water-level fluctuation induced by the reservoir regulation. This tool was also helpful in assessing the environmental impacts of the dam operation.
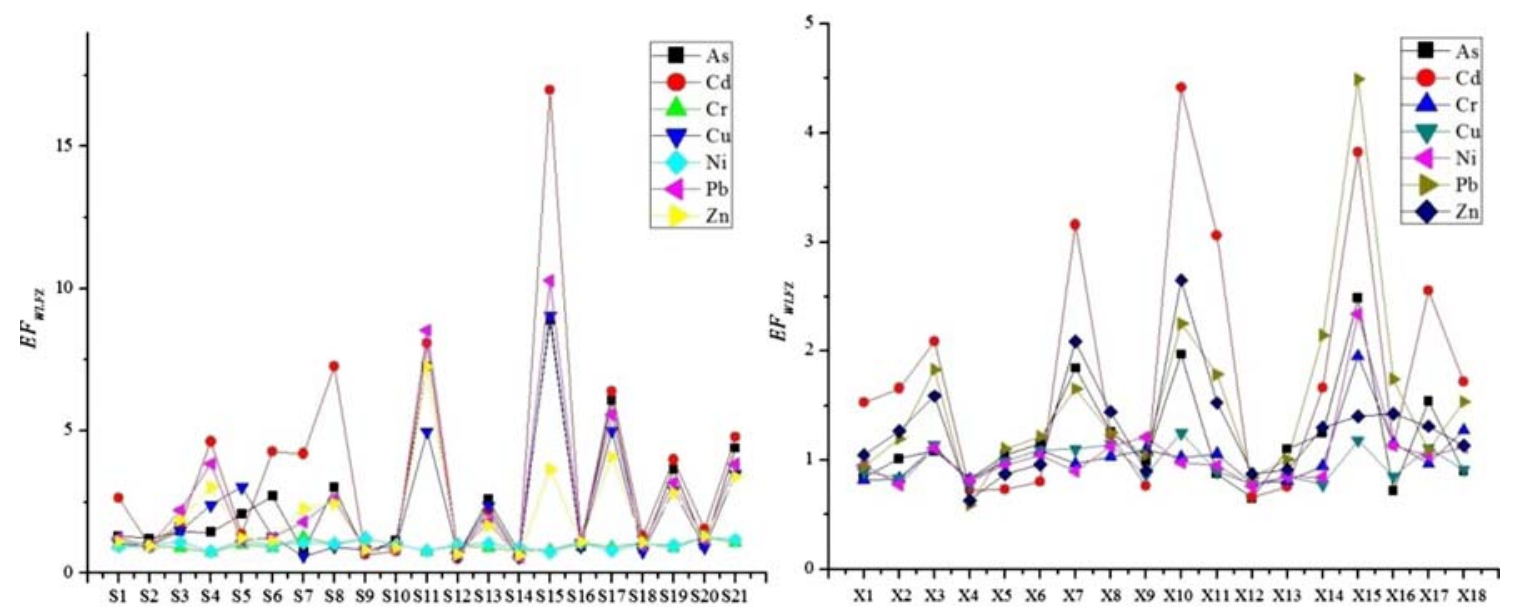

Fig. $6 W_{\mathrm{WLFZ}}$ values of the elements at the sample sites in upstream and downstream WLFZs of the Manwan Dam. The sites upstream are represented to the left, and the sites downstream are represented to the right 


\section{Conclusions}

To investigate the heavy metals in the WLFZs upstream and downstream of the Manwan Dam, soil samples were collected and analysed in this study. Results showed that spatial variation of heavy metals existed in WLFZs upstream and downstream. Most of the studied element concentrations in the upstream WLFZ were significantly higher than those in the downstream WLFZ due to the Manwan Dam trap and the fast water flow velocity adjacent to the downstream waters; only $\mathrm{Cr}$, $\mathrm{Ni}$ and $\mathrm{Fe}$ revealed significant variations between upstream and downstream IRZs. Chromium upstream and the $\mathrm{Cd}, \mathrm{Pb}$ and $\mathrm{Zn}$ downstream revealed significant differences between the WLFZs and IRZs, which could be partly related to the deposition and material exchange among those metals caused by water-level fluctuation during submergence. In addition, heavy metal concentrations at different water elevations revealed no significant differences, which could be attributed to insufficient flooding time or the small elevation interval.

Most of the studied element concentrations in the soil in WLFZs and IRZs upstream and downstream of Manwan Dam did not exceed guidelines of Chinese quality standard, except for As and $\mathrm{Cd}$. The EF indices showed that most of the studied elements were slightly enriched in the WLFZs and that Cd and As revealed moderately severe enrichment degrees. Fourteen of 21 sites in the upstream revealed moderate ecological risk and above, and half of the sites in the downstream revealed moderate ecological risk and above. Higher enrichment levels in the WLFZs than in the IRZs could indicate that the waterlevel fluctuation during the submergence period brought additional sources. The higher ecological risk in the WLFZs indicated that submergence increased the risk level.

As for the sources of the heavy metals in the sampling sites, PCA results revealed that the heavy metal sources in the WLFZs could be divided into two categories: natural factors and anthropogenic factors. The anthropogenic inputs mainly came from the application of fertilizers and pesticides, the pigment and electroplating industries, the metal mining and smelting industries and tributary exploitation. The PCA comparative results indicated that the upstream primary pollutants were different in the WLFZs than in the IRZs, which could be related to the submergence.

In order to assess the enrichment degree caused by the water-level fluctuation after submergence, a modified enrichment factor index was proposed and applied in this study, and the results confirmed the applicability of the formula. These results examined the contamination, sources and distribution of the heavy metals in the upstream and downstream WLFZs of the Manwan Dam and could contribute to reservoir management and maintenance. This study suggests strict administration over the discharge of industrial and agricultural inputs is needed to reduce the contamination and risk levels in the WLFZs. Assessing the heavy metal contamination of soils in WLFZs could be an important first step to the rational management of the dam operation. However, more research is needed to (1) explore the water-level fluctuation impacts on the soil quality in the WLFZs and (2) analyse the riparian habitat changes due to the water regulation by Manwan Dam.

Acknowledgements This research was funded by the Nonprofit Environment Protection Specific Project of China (no. 201209029-4).

\section{References}

Acevedo-Figueroa D, Jiménez B, Rodriguez-Sierra C (2006) Trace metals in sediments of two estuarine lagoons from Puerto Rico. Environ Pollut 141:336-342

Audry S, Schäfer J, Blanc G, Jouanneau JM (2004) Fifty-year sedimentary record of heavy metal pollution $(\mathrm{Cd}, \mathrm{Zn}, \mathrm{Cu}, \mathrm{Pb})$ in the Lot River reservoirs (France). Environ Pollut 132:413-426

Avila-Pérez P, Balcázar M, Zarazúa-Ortega G, Barceló-Quintal I, DíazDelgado C (1999) Heavy metal concentrations in water and bottom sediments of a Mexican reservoir. Sci Total Envrion 234:185-196

Bai J, Cui B, Xu X, Ding Q, Gao H (2009) Heavy metal contamination in riverine soils upstream and downstream of a hydroelectric dam on the Lancang River, China. Environ Eng Sci 26:941-946

Birch G (2003) A scheme for assessing human impacts on coastal aquatic environments using sediments. Coastal GIS, 14

Censi P, Spoto SE, Saiano F, Sprovieri M, Mazzola S, Nardone G, Di Geronimo SI, Punturo R, Ottonello D (2006) Heavy metals in coastal water systems. A case study from the northwestern Gulf of Thailand. Chemosphere 64(7):1167-1176

Covelli S, Fontolan G (1997) Application of a normalization procedure in determining regional geochemical baselines. Environ Geol 30(1/2): 34-45

Dickinson W, Dunbar G, McLeod H (1996) Heavy metal history from cores in Wellington Harbour, New Zealand. Environ Geol 27:59-69

Fang D (1998) Utilizable rock mass quality standard research on Manwan concrete dam foundation. Yunnan Hydropower Technol 3:23-27, in Chinese

Fearnside PM (2005) Brazil's Samuel Dam: lessons for hydroelectric development policy and the environment in Amazonia. Environ Manage 35:1-19

Feng H, Han X, Zhang W, Yu L (2004) A preliminary study of heavy metal contamination in Yangtze River intertidal zone due to urbanization. Mar Pollut Bull 49:910-915

Gan Q, Zhou L, Zhou X, Mei Z, Zhang Y (2008) The study on operating water level dynamic control of the Dachaoshan Reservoir during the flood season. Yunnan Water Power 3:1-5 (in Chinese)

Ghrefat H, Yusuf N (2006) Assessing Mn, Fe, Cu, Zn, and Cd pollution in bottom sediments of Wadi Al-Arab Dam, Jordan. Chemosphere 65: 2114-2121

Gonzáles-Macías C, Schifter I, Lluch-Cota DB, Méndez-Rodríguez L, Hernández-Vázquez S (2006) Distribution, enrichment and accumulation of heavy metals in coastal sediments of Salina Cruz Bay, Mexico. Environ Monit Assess 118:211-230

Hakanson L (1980) An ecological risk index for aquatic pollution control. A sedimentological approach. Water Res 14:975-1001

He D, Feng Y, Gan S, Magee D, You W (2006) Transboundary hydrological effects of hydropower dam construction on the Lancang River. Chinese Sci Bull 51:16-24

Karadede H, Ünlü E (2000) Concentrations of some heavy metals in water, sediment and fish species from the Atatürk Dam Lake (Euphrates), Turkey. Chemosphere 41:1371-1376 
Kummu M, Varis O (2007) Sediment-related impacts due to upstream reservoir trapping, the Lower Mekong River. Geomorphology 85: 275-293

Li L (1999) Water quality status assessment and causal analysis of Lancang River. Acta Geographica Sinica 54:127-134

Lin YP, Teng TP, Chang TK (2002) Multivariate analysis of soil heavy metal pollution and landscape pattern in Changhua county in Taiwan. Landscape Urban Plan 62:19-35

Loska K, Wiechula D (2003) Application of principal component analysis for the estimation of source of heavy metal contamination in surface sediments from the Rybnik Reservoir. Chemosphere 51: $723-733$

Mays P, Edwards G (2001) Comparison of heavy metal accumulation in a natural wetland and constructed wetlands receiving acid mine drainage. Ecol Eng 16:487-500

Mwamburi J (2003) Variations in trace elements in bottom sediments of major rivers in Lake Victoria's basin, Kenya. Lake Reserv Res Manage 8:5-13

NSSO (1995) Chinese soil genus records, 3. China Agriculture, Beijing Nyamangara J (1998) Use of sequential extraction to evaluate zinc and copper in a soil amended with sewage sludge and inorganic metal salts. Agr Ecosyst Environ 69:135-141

Oregioni B, Aston S (1984) IAEA Monaco Laboratory International Report (cited from reference methods in pollution studies no. 38 , UNEP, 1986)

Qiao S, Jiang J, Xiang W, Tang J (2005) Distribution of heavy metals in sediments in lakes in Wuhan with assessment on their potential ecological risk. Resour Environ Yangtze Basin 14:353-357 (in Chinese)

Qiao S, Yang Z, Pan Y, Guo Z (2007) Metals in suspended sediments from the Changjiang (Yangtze River) and Huanghe (Yellow River) to the sea, and their comparison. Estuar Coast Shelf S 74(3):539-548

Rodríguez L, Ruiz E, Alonso-Azcárate J, Rincón J (2009) Heavy metal distribution and chemical speciation in tailings and soils around a $\mathrm{Pb}-\mathrm{Zn}$ mine in Spain. J Environ Manage 90:1106-1116

Rubio B, Nombela M, Vilas F (2000) Geochemistry of major and trace elements in sediments of the Ria de Vigo (NW Spain) an assessment of metal pollution. Mar Pollut Bull 40:968-980

SEPAC (1990) Chinese element background value for soils. State environmental protection administration of China. Science, Beijing

SEPAC (1995) Chinese environmental quality standard for soils (GB 15618-1995).http://kjs.mep.gov.cn/hjbhbz/bzwb/trhj/trhjzlbz/ 199603/t19960301 82028.htm

SEPAC (2004) The technical specification for Soil environmental monitoring. Environmental Press of China, Beijing

SPEAC (1990) Chinese element background value for soils. Science, Beijing

Srinivasa Gowd S, Ramakrishna Reddy M, Govil P (2010) Assessment of heavy metal contamination in soils at Jajmau (Kanpur) and Unnao industrial areas of the Ganga Plain, Uttar Pradesh, India. J Hazardous Mater 174:113-121

Tam N, Wong Y (2000) Spatial variation of heavy metals in surface sediments of Hong Kong mangrove swamps. Environ Pollut 110:195-205

Wang X, Fu W, Xie F, Pu P, Peng J (2010) The distribution characteristic of soil heavy metals and their influencing factors in water-level- fluctuating zones of the Three Gorges reservoir area. Res Soil Water Conserv 17:267-270 (in Chinese)

Wang C, Liu S, Zhao Q, Deng L, Dong S (2012a) Spatial variation and contamination assessment of heavy metals in sediments in the Manwan Reservoir, Lancang River. Ecotox Environ Safe 82:32-39

Wang Y, Lei B, Yang S, Zhang S (2012b) Concentrations and pollution assessment of soil heavy metals at different water-level altitudes in the draw-down areas of the Three Gorges Reservoir. Environ Sci 33(2):612-617

$\mathrm{Xu} \mathrm{J}$, Chen L (2005) Analysis on environmental impact and ecorestoration of large hydropower station construction - take the Manwan Hydropower of Yunnan as a case. Yunnan Environ Sci 24:14-18

Yanqun Z, Yuan L, Jianjun C, Haiyan C, Li Q, Schvartz C (2005) Hyperaccumulation of $\mathrm{Pb}, \mathrm{Zn}$ and $\mathrm{Cd}$ in herbaceous grown on lead-zinc mining area in Yunnan, China. Environ Int 31:755-762

Ye C, Li S, Zhang Y, Zhang Q (2011) Assessing soil heavy metal pollution in the water-level-fluctuation zone of the Three Gorges Reservoir, China. J Hazard Mater 191(1-3):366-372

Ye C, Li S, Zhang Y, Tong X, Zhang Q (2013) Assessing heavy metal pollution in the water level fluctuation zone of China's Three Gorges Reservoir using geochemical and soil microbial approaches. Environ Monit Assess 185(1):231-240

Youssef DH, El-Said GF (2011) Assessment of some heavy metals in surface sediments of the Aqaba Gulf, Egypt. Environ Monit Assess 180(1-4):229-242

Yuan C, Shi J, He B, Liu J, Liang L, Jiang G (2004) Speciation of heavy metals in marine sediments from the East China Sea by ICP- MS with sequential extraction. Environ Int 30:769-783

Zhang Y, Liu J, Wang L (2005) Changes in water quality in the downstream of Lancang Jiang river after the construction of Manwan hydropower station. Resour Environ Yangtze Basin 14:500-506, in Chinese

Zhang L, Ye X, Feng H, Jing Y, Ouyang T, Yu X, Liang R, Gao C, Chen W (2007a) Heavy metal contamination in western Xiamen Bay sediments and its vicinity, China. Mar Pollut Bull 54:974-982

Zhang M, Wang L, He Z (2007b) Spatial and temporal variation of nitrogen exported by runoff from sandy agricultural soils. J Environ Sci-China 19:1086-1092

Zhang W, Feng H, Chang J, Qu J, Xie H, Yu L (2009) Heavy metal contamination in surface sediments of Yangtze River intertidal zone: an assessment from different indexes. Environ Pollut 157:15331543

Zhao T (1996) The review and prospect of plant zinc nutrition. J Hebei Agr Univ 19(1):102-107 (in Chinese)

Zhao Q, Liu S, Zhang Z, Deng L (2011) Effects of Manwan hydropower exploitation on dynamic changes of landscape pattern in related reservoir area. Chin J Ecol 30(10):2343-2350, in Chinese

Zhao Q, Liu S, Deng L, Yang Z, Dong S, Wang C, Zhang Z (2012) Spatio-temporal variation of heavy metals in fresh water after dam construction: a case study of the Manwan Reservoir, Lancang River. Environ Monit Assess 184(7):4253-4266

Zoller WH, Gladney E, Duce RA (1974) Atmospheric concentrations and sources of trace metals at the South pole. Science 183(4121):198 200 